\section{Broadening the perspective}

\section{Geoff Bailey}

European Economic Prehistory: A New Approach.

By Robin Dennell.

Academic: 1983. Pp.214. f15, \$26.

THEMATIC approaches to prehistoric archaeology are no longer a novelty. Analysis of general issues rather than reconstruction of particular archaeological sites, areas and periods, and an emphasis on generalization and explanation rather than the relentless cataloguing of human cultural diversity for its own sake, are now well-established ideals of modern archaeological research. Few specialist reports fail to mention the ecological, social or cognitive implications of their subject matter, even if such comment is often little more than lip service to current intellectual fashion.

Yet general accounts of prehistory have tended to convey a quite different impression. The ever-growing mass of archaeological data has resulted in syntheses focused on ever smaller areas and periods, or in global treatments in which the continuum of prehistory, for want of any better organizing principle, is divided into social and technological stages of development inherited from nineteenthcentury preconceptions. Palaeolithic Savages and Neolithic Barbarians, to say nothing of the ghostly ancestors of Civilization, still stalk the pages of the modern literature, lurking behind the lengthening lists of sites and radiocarbon dates, and stones and bones, and pots and artefacts of every sort.

Robin Dennell's European Economic Prehistory provides a long overdue break with nineteenth-century conventions in its attempt to provide an overview of central themes in European prehistory from the earliest human occupation over 500,000 years ago up to the spread of farming during the Neolithic period. It is neither wholly about Europe, since most issues during this time span cannot adequately be understood except by reference to a broader geographical context, nor is it solely about prehistoric economies. As Dennell emphasizes, economic prehistory should not be merely a description of past diets, nor should it be the expression of a narrow materialist philosophy. Rather it provides a unifying perspective on a whole range of issues in human physical and cultural evolution.

The earliest occupation and subsequent expansion of human settlement, the appearance of modern social and cognitive patterns, the responses of late Pleistocene populations to the extreme environments of the Last Glacial and the subsequent deglaciation, and the adoption of novel food resources and the spread of farming economies - these are the highlights of Dennell's approach. Theoretical concepts are combined with a clear statement of the practical difficulties and controversies involved in the interpretation of primary archaeological and palaeontological data; compendious detail is avoided without courting superficiality or eccentricity. The conventional subdivisions of the Palaeolithic period are critically examined and found wanting as useful markers of behavioural change, while the attack on the Neolithic revolution as a useful concept in European prehistory is short, sharp and lethal.

This is very much a personal view - the ideas incorporated within the book will stimulate the specialist as well as the general reader, who will find in it a short but informed account of changing perspectives on our prehistoric origins. It should do much to enlighten those for whom the long stretches of the Pleistocene period seem like a dismal dark ages before the rise of civilization.

Geoff Bailey is a Lecturer in the Department of Archaeology, University of Cambridge.

\section{Hamburger heaven}

\section{Robert Ubell}

\section{The Social Transformation of American} Medicine.

By Paul Starr.

Basic Books: 1982/Harper \& Row: 1983.

Pp.514. \$24.95, £21.50.

MosT readers of Nature will be aware of the unusual organization of health care in the United States - a medical practice largely in the hands of private ("fee-for-service") doctors. Still, it is worth repeating for American readers that medical care in most other advanced capitalist nations is delivered by physicians serving under national health insurance schemes. Only in America does the siren of an ambulance rushing to save your life also signal the need to pull out your cheque-book or private insurance card.

The struggle for national health insurance in the United States and its relentless suppression is one of the principal motifs in this remarkable book. Paul Starr, a Harvard sociologist, reveals the forces at work in the creation of American medicine; acting like a geologist studying plate tectonics, he uncovers broad changes, shifts and displacements that helped mould the American medical landscape. By charting social and economic struggles, Starr draws a kinetic map showing how the private practitioner came to occupy the peak of power

Starr frames his analysis by going back to the colonial period, when health care was largely the province of women who routinely treated their families at home. As midwives, women assumed primary responsibility for childbirth. Prominent as "lay practitioners", women also frequently entered the medical profession as the equals of men. By 1893-1894, women accounted for ten per cent or so of students at co-educational medical institutions, in addition to taking all of the places at women's medical colleges. In some cities - Boston, for one - nearly twenty per cent of those practising were women. Strikingly, by the turn of the century, male doctors had taken over almost completely. Just as women cooks are usurped by male chefs when status and economic gain are at stake, so medicine became a male preserve.

Toppling any misconception that doctors have always held a dominant position in America, Starr shows that a medical career in the middle of the nineteenth century guaranteed neither prestige nor security. In 1832 on learning that his son was about to become a doctor, one father wailed:

If I had known this, I certainly would not have sent you to college .... it is a profession for which I have the utmost contempt. There is no science in it. There is no honour to be achieved in it; no reputation to be made.

Throughout most of the century, American populism had opposed whatever privilege and social distinction doctors claimed. And because academic medicine had not yet secured any decisive victories, many Americans held that it was wiser to treat illness at home rather than turn to physicians who knew as much as they did. While resistance to professional medicine has often been portrayed as hostility to science, Starr contends that popular scepticism was hardly unreasonable, given what we know about the effectiveness of early nineteenth-century therapy. But as medicine moved into the new scientific orbit, it could finally be defended as therapeutically valuable. The "domocratic" ideal - that clinical knowledge should be easily accessible and universally practised - shrank in the face of the growing complexity and efficacy of medicine. Americans, by the 1920s, had changed their minds. They no longer believed they could heal themselves without professional intervention.

By the end of the first part of this intricately argued book, Starr has pursued his story through to the Great Depression. By then, American physicians had secured their unprecedented authority - and more. "Acknowledged skills and cultural authority", Starr remarks, "are to the professional classes what land and capital are to the propertied. They are the means of securing income and power."

How did they do it? Other sectors of American society had fallen under the sway of the corporation or belonged to the state. For Starr, the answer, while not simple, is the hinge on which the door swings open 